\title{
EMPREGO DE ACRÔNIMOS EM OPERAÇÕES DE COMBATE A INCÊNDIOS: DO CONCEITO DE CARGA INCÊNDIO AO DE TAXA DE LIBERAÇÃO DE CALOR
}

\begin{abstract}
André Telles Campos ${ }^{1}$
Paulo Fernando Leal de Holanda Cavalcanti ${ }^{2}$

Eduardo de Assis Lima ${ }^{3}$

RESUMO

A tomada de decisão em operações de combate a incêndios é tarefa bastante complexa, pois envolve diversos fatores relacionados à prestação do socorro em si e aos conhecimentos adquiridos ao longo da vida, além da pressão inerente à atividade emergencial. Durante o atendimento a uma ocorrência de incêndio urbano várias demandas se sobrepõem, comprimindo o espaço para decisões estruturadas. Adicionalmente, o surgimento de muitas demandas em um curto intervalo de tempo pode fazer com que o comandante de socorro foque excessivamente em tarefas pontuais, deixando de lado aquilo que precisa ser feito para resolver a situação como um todo. É o que se convencionou chamar estreitamento perceptivo ou visão de túnel. Com o objetivo de auxiliar os bombeiros nessas ocorrências, foram criados acrônimos para nortear e padronizar as decisões dos comandantes do incidente. Bombeiros norte-americanos desenvolveram em 2014 o SLICE-RS, um acrônimo para guiar o comandante de socorro de primeira resposta, que integra conhecimentos provenientes da teoria do fogo às atividades estratégicas do combate a incêndio urbano. Por outro lado, permanece a lacuna de como organizar, de forma mnemônica e prática, o que fazer no nível de segunda resposta. Nesse sentido, o presente artigo propõe a utilização do acrônimo CRISE-B (ou SWARMS, em inglês) como meio de orientar as ações do comandante de socorro em ocorrências de incêndio em segunda resposta.
\end{abstract}

Palavras-chave: Acrônimos; Tática de combate a incêndio; Teoria do fogo.

\footnotetext{
${ }^{1}$ Tenente-Coronel do Corpo de Bombeiros Militar do Distrito Federal. Físico e Engenheiro Mecânico. Doutor em Física pela Universidade de Brasília. Instrutor de dinâmica de incêndio no CBMDF.

${ }^{2}$ Major do Corpo de Bombeiros Militar do Distrito Federal. Graduado em Educação Física e Pós-graduado em Administração Corporativa pela Universidade de Brasília - UnB. Instrutor de Combate a Incêndio pelo CBMDF e Fire Behaviour Training Instrutor pela The Fire Service College Moreton-in-Marsh, Inglaterra.

${ }^{3}$ Capitão do Corpo de Bombeiros Militar do Distrito Federal. Farmacêutico e Pós-graduado em Vigilância Sanitária pela Universidade Estadual do Goiás - UEG. Instrutor de Combate a Incêndio Urbano pelo CBMDF e CBMGO (Instrutor Flashover).
} 


\title{
ACRONYMS' EMPLOYMENT ON FIRE OPERATIONS: FROM FIRE LOAD CONCEPT TO HEAT RELEASE RATE
}

\begin{abstract}
Decision making in firefighting operations is a very complex task, as it involves several elements related to the emergence response itself and to the knowledge acquired throughout life, besides to the pressure inherent in emergency activity. During the attendance to an urban fire call several demands overlap, compressing the space for structured decisions. In addition, the emergence of many demands in a short period of time can cause the incident commander to focus excessively on specific tasks, leaving aside what needs to be done to resolve the situation as a whole. This is what is conventionally called perceptive narrowing or tunnel vision. In order to assist firefighters on these call responses, acronyms were created to guide and standardize the decisions of the incident commanders. In 2014, North American firefighters developed SLICE-RS, an acronym to guide the first response commander, which integrates knowledge from the theory of fire behaviour into the strategic activities of urban firefighting. On the other hand, remains a gap in how to organize, in a mnemonic and easy way, what to do at the second response level. In this sense, this article proposes the use of the acronym SWARMS (or CRISE-B, in Portuguese) as a means of guiding the actions of the incident commander on the fire event when performing the second response.
\end{abstract}

Key-words: Acronyms. Firefighting tactics. Fire dynamics. 


\section{INTRODUÇÃO}

O processo de tomada de decisão na atividade operacional de bombeiros geralmente é guiado pela experiência adquirida durante anos de profissão. Klein (1999) relata que a experiência de comandantes de socorro permitia que eles identificassem uma reação razoável como a primeira que considerassem e assim não perderiam tempo pensando em outras. A isso 0 autor denomina decisão baseada no reconhecimento.

Uma nova era de elementos construtivos, de revestimento e mobiliários das edificações contemporâneas exigiu o desenvolvimento de novas técnicas e novas abordagens para uma antiga batalha travada pelos bombeiros e que, por sua vez, exigiram novas maneiras de enfrentamento e planejamento de ações.

Estudo publicado pela Chief Fire Officers Association - CFOA com chiefs do Reino Unido corrobora com essa constatação. Segundo essa pesquisa os comandantes de socorro muitas vezes contornaram a fase de planejamento, indo diretamente da fase de avaliação situacional para a ação, fato que ocorreu em cerca de $80 \%$ dos casos (CFOA, 2015).

Com o objetivo de auxiliar o bombeiro na tomada de decisão em ocorrências de combate a incêndios urbanos, foram criados diversos acrônimos, sobretudo nos Estados Unidos - EUA, para nortear e padronizar as ações dos comandantes de incidente sob condições estressantes. No ano de 2014 foi criado o SLICE-RS, após estudos em conjunto do National Institute for Standards and Technology - NIST e Underwriters Laboratories Firefighter Safety Research Institute - UL com a International Society of Fire Service Instructors - ISFSI, que, além de guiar o comandante de socorro de primeira resposta, buscava integrar conhecimentos provenientes da teoria do fogo às atividades estratégicas do combate a incêndio urbano.

Por outro lado, permanece a lacuna do que fazer na segunda resposta tanto no nível tático quanto operacional. Nesse sentido, o presente artigo 
propõe a utilização do acrônimo CRISE-B (SWARMS) que é uma metodologia idealizada no Corpo de Bombeiros Militar do Distrito Federal - CBMDF.

\section{ELEMENTOS DE TEORIA DO FOGO}

No contexto do combate a incêndio estrutural, conhecer significa compreender a dinâmica do incêndio, como este se desenvolve e se comporta em estruturas confinadas e abertas (UL, 2018).

Apesar de todo conhecimento produzido, o que se observou por algum tempo foi o distanciamento e a pouca integração da estratégia e da tática de combate a incêndio urbano daquilo que se convencionou chamar de "teoria do fogo". Como se sabe, a ciência do fogo é o aspecto basilar do combate a incêndio urbano em qualquer corporação de bombeiros no mundo, possibilitando que fossem conhecidos diversos fenômenos até então inexplorados e que por anos haviam ceifado a vida de centenas de bombeiros ao redor do mundo.

Um aspecto relevante nesse sentido é entender como se processa a ignição dos materiais combustíveis. A ignição pode ser definida como o processo no qual uma reação exotérmica rápida é iniciada, então se propaga e provoca transformação nos materiais envolvidos, produzindo aumento de temperatura bem superior à do ambiente (DRYSDALE, 2011).

Os combustíveis sólidos precisam passar por uma decomposição térmica, denominada pirólise, para passar à fase gasosa e iniciar a queima. Um contraexemplo é a parafina da vela, que derrete e vaporiza para então queimar. Porém, quase todos os combustíveis sólidos não apresentam fase líquida ou gasosa, ou seja, eles precisam ser degradados (sofrer quebra de moléculas) para queimar (LENTINI, 2013).

O parâmetro chave a ser estudado é a temperatura da superfície do material. Considerando fluxo de calor contínuo, a ignição ocorrerá quando a temperatura superficial igualar ou ultrapassar a temperatura de ignição do material combustível. Recordando que a temperatura de ignição é definida 
como a temperatura mínima a partir da qual o combustível libera vapores voláteis suficientes para que a combustão se dê de forma sustentada após a retirada da fonte de calor (QUINTIERE, 1998).

Obviamente outros fatores influenciam na ignição dos materiais: propriedades térmicas, densidade, espessura e a forma como se dá o aquecimento. Por exemplo, a ignição da madeira pode ocorrer com temperaturas superficiais de $200{ }^{\circ} \mathrm{C}$, se aquecida por fluxo de calor convectivo, ou temperaturas de $300{ }^{\circ} \mathrm{C}$ a $400 \stackrel{\circ}{\circ}$, se aquecida por fluxo de calor radiativo. $\mathrm{O}$ fluxo de calor líquido deve ser suficiente para elevar a temperatura superficial até a temperatura de ignição. Por padrão, adota-se o fluxo de calor radiativo. No caso da madeira, esse fluxo deve ser de, no mínimo, $12 \mathrm{~kW} / \mathrm{m}^{2}$ (QUINTIERE, 1998).

A modernização dos elementos construtivos, mobiliário, revestimentos e tecidos fez com que a dinâmica dos incêndios urbanos fosse transformada. Quanto maior a quantidade de materiais sintéticos nos elementos componentes das residências contemporâneas, maior será a taxa de liberação de calor e, consequentemente, um aumento na velocidade de transição das fases do incêndio, potencializando as condições para que o incêndio se torne limitado pela ventilação antes da intervenção dos bombeiros.

Além disso, comportamentos afetos à progressão rápida dos incêndios que, no passado próximo, levavam 30 (trinta) ou 40 (quarenta) minutos para ocorrerem, são observados atualmente em menos de 10 (dez) minutos. Estudos comprovam a ocorrência da generalização do incêndio - flashover, uma característica da rápida progressão do incêndio, em menos de 5 (cinco) minutos do início do incêndio (KERBER, 2012).

A taxa de liberação de calor - HRR (do inglês Heat Release Rate), ou mais apropriadamente taxa de liberação de energia, é o fator isolado mais importante para caracterizar o comportamento do fogo. Por meio dela tem-se noção da potência do fogo e de sua capacidade para causar danos. Normalmente a HRR é medida em kilowatts ou megawatts. Ela é influenciada 
por diversas variáveis, incluindo não só propriedades relacionadas ao material combustível em si (quantidade, tipo e orientação), mas também com o processo de combustão dentro da chama e as formas de transferência de calor no ambiente, além de condições de ventilação (QUINTIERE, 1998).

$O$ desenvolvimento do incêndio num compartimento pode ser descrito por meio de uma curva de HRR versus tempo. E nesse ponto convém destacar o conceito de carga incêndio, tão conhecido dos bombeiros. Trata-se da energia calorífica total que pode ser liberada pela combustão completa do material combustível em análise. Em outras palavras, a carga incêndio é o resultado da integração da curva de HRR ao longo do tempo de queima (CBMDF, 2009a).

A carga incêndio é largamente utilizada em normatização de análise de riscos de incêndio. No entanto, ela não consegue retratar a realidade dinâmica do incêndio, visto que a energia total devida à queima do material nunca será liberada de uma só vez, ao mesmo tempo. A curva de HRR, por sua vez, permite avaliar o pico de liberação de energia, o tempo de duração da queima e, mais importante aqui, possibilita fazer uma correlação com a quantidade de água necessária para debelar o incêndio e os respectivos modos de ataque que as guarnições de bombeiros utilizam para o resfriamento dos gases quentes da combustão (CBMDF, 2019).

\section{ASPECTOS DA TÁTICA DE COMBATE A INCÊNDIOS}

O comando no nível estratégico tem desafios evidentes a depender do tamanho e da complexidade do evento e no nível tático não é menos difícil. Nessa área, as condições dinâmicas da cena de emergência, frequentemente, irão demandar do comandante que decisões difíceis sejam adotadas em pouco tempo sem o benefício de ter a informação completa e precisa. Uma combinação de treinamento, experiência, recursos adequados e informação pode auxiliar o comandante de socorro no processo de tomada de decisão (BRYANT, 2014). 
O comandante de incidente de incêndio precisa gerenciar situações altamente desafiadoras e de alta pressão. Estas situações de pressão são entendidas à medida que a situação concreta se desenrola e exige que 0 comandante tome muitas e variadas decisões sobre recursos e táticas operacionais, planejar como lidar com a emergência e comunicar esses planos de modo que as equipes entendam (CFOA, 2015).

Nesse sentido, o primeiro comandante na cena tem uma das posições mais desafiadoras no cenário de emergência, pois suas decisões irão afetar o resultado do incêndio, conduzir o destino da ocorrência ao sucesso ou fracasso (PRZIBOROWSKI, 2015; NORMAN, 2012).

Tomar decisões eficazes nos momentos iniciais do atendimento é extremamente difícil. O primeiro socorro chega em cena enquanto o reforço já está próximo, pessoas frenéticas, bombeiros pedindo por atribuições e há pressão para fazer algo e fazê-lo já. O primeiro comandante de socorro não dispõe de muito tempo para tomar decisões de qualidade, tendo em vista a pressão e a quantidade limitada de informações com que tem que lidar (PRZIBOROWSKI, 2015).

Caberá ao primeiro comandante do incidente que chegar ao local o desenvolvimento de um plano de ação básico, mesmo com poucas informações, mas que deve conter a definição estratégica correta (ofensiva ou defensiva). À medida que a situação evolui, a qualidade das informações melhora e o plano também é incrementado com os relatos dos bombeiros (MORRIS, 2012).

O desenvolvimento da situação pode fazer com que as condições de combate piorem e, com isso, o comandante do incidente deve estar preparado para evacuar rapidamente o prédio antes que os bombeiros sejam feridos. $O$ plano de ação, assim como as condições ambientais é dinâmico e deve se adaptar às condições que são apresentadas no incidente (MORRIS, 2012).

Os bombeiros que tomam decisões devem estar completamente conscientes das consequências de suas ações, devendo estar munidos de um 
processo de tomada de decisão adequado que abranja o entendimento de vários princípios de combate a incêndio, que devem estar solidificados na mente do comandante de socorro (NORMAN, 2012).

Em algumas situações, os erros que ocorreram nos estágios iniciais do combate a incêndios, relacionados a tomada de decisão do comando, tiveram o maior impacto nos resultados do incidente. Foi nos primeiros 60 (sessenta) segundos que ações ou decisões críticas poderiam ter feito a maior diferença na localização e salvamento de ocupantes presos. Nos primeiros 5 (cinco) minutos que o plano de implantação definiu um ponto "sem retorno imediato" que pode ter impactado muito o sucesso de toda a operação de combate a incêndios (GRIMWOOD, 2017).

Foi observado ainda que em algumas situações os bombeiros foram colocados em um aparente "ponto de não retorno", por medo de perder o controle do incêndio, mesmo com recursos insuficientes e com a exposição ao risco aumentando de maneira vertiginosa. É nesse ponto que a cadeia de erros pode ser quebrada pela chegada de um segundo comandante à cena. Pode ser que nesse ponto crítico dentro dos 12 primeiros minutos de uma resposta inicial que a decisão do comando de retirar e reagrupar para reimplantação podia ter salvado várias vidas de bombeiros (GRIMWOOD, 2017).

Um segundo comandante de socorro chegando ao local nos primeiros 12 minutos pode ter a vantagem de entrar na cena com um novo olhar, sem vícios. Entretanto, é preciso coragem e experiência para ser capaz de fazer adequadamente a manutenção da estratégia ou mudar a direção das ações, especialmente se isso significar retirar as equipes para o exterior e começar de novo (GRIMWOOD, 2017).

\section{Gerenciamento de risco na cena de incêndio}

O gerenciamento de riscos engloba várias medidas que podem ser usadas para limitar, reduzir ou eliminar a probabilidade de ocorrer um resultado indesejável. Inclui também as medidas que podem ser usadas para limitar, 
reduzir ou eliminar a magnitude prevista de resultado indesejável, caso ele venha a ocorrer (FEMA, 2018).

Conscientemente ou não, o trabalho de um departamento de bombeiros está repleto de gerenciamento de riscos. Desde a decisão de quando colocar o EPR até o diâmetro da mangueira a ser utilizado no combate, o bombeiro está sempre conduzindo subconscientemente uma análise de custo-benefício, ou seja, trata-se de uma avaliação de quanto risco se está disposto a aceitar em troca de eficiência na realização do trabalho (WAGNER, 2019).

Vários conceitos relacionados à segurança são comuns a todas as emergências de incêndio, sendo que alguns cuidados podem ser realizados antes do incidente e outros quando o incidente ocorre. São incluídos no bojo dos conceitos comuns da cena de incidente a atribuição de um oficial de segurança de incidentes, uso de EPI adequado, sistema de controle de pessoal no incêndio, equipe de intervenção rápida instalada e o estabelecimento de uma área de reabilitação e descontaminação (ANGLE et al., 2020).

Grimwood (2008) reforça que o risco aos bombeiros é o fator mais importante considerado pelo comandante de socorro e, além das ações citadas acima, inclui ainda: opções estratégicas bem definidas, seguimento de procedimentos operacionais padrão - POPs, treinamento efetivo, controle de pessoal e de ar dos EPR, gerenciamento efetivo do incidente e comunicações, guarnições de back-up para ataque interno (two-in / two-out), avaliação regular de mudanças de condições do incidente, entre outros.

Atualmente, a percepção é de mudança, em que pese haver o respeito pela bravura e a coragem, principalmente quando uma situação envolve salvar vidas. Em muitos casos, o que se vai observar é a limitação da exposição do pessoal a riscos que eles podem estar dispostos a aceitar por si próprios. A definição de risco aceitável para um departamento de bombeiros pode ser mais conservadora do que o nível de risco que um bombeiro individual pode aceitar livremente. No sistema de valores atual, os oficiais de nível mais alto são 
frequentemente mais responsáveis por limitar a exposição ao risco do que por exigir coragem de suas forças (FEMA, 2018).

Um bom exemplo disso é o que foi observado na cidade de Flint em Detroit nos Estados Unidos. Nessa cidade, $40 \%$ dos incêndios estruturais confirmados se davam em edificações vazias ou abandonadas e foi constatado no departamento de bombeiros daquela cidade que a taxa de lesões em bombeiros em incêndios em edificações vazias ou abandonadas era maior que o triplo da média nacional, segundo dados da NFPA (GRIMWOOD, 2008).

\section{Ataque ofensivo ou defensivo}

No que tange à decisão estratégica, o Comandante do Incidente deve decidir se arriscar a vida dos bombeiros terá um resultado positivo, como salvar as vidas das vítimas dentro da estrutura em chamas, ou não. Essa decisão ditará se o incêndio será abordado de maneira ofensiva ou defensiva (IFSTA, 2013).

Um ataque ofensivo é a estratégia preferida sempre que as condições e os recursos permitirem um ataque interno. Por sua vez, uma decisão defensiva limita a operação para o exterior, geralmente resultando em uma perda maior de propriedade e limitando as opções de salvamento (KLAENE; LAKAMP, 2020).

Quando uma Unidade de bombeiros chega à cena de socorro, várias ações vêm à mente dos bombeiros - é a avaliação (também chamada de "sizeup"). As ações que serão executadas, independentemente do tipo de incidente encontrado, seguirão quase sempre a mesma sequência: localizar, confinar e extinguir (NORMAN, 2012).

Aquilo que se precisa para combater um incêndio ofensivamente difere daquilo que é necessário para uma abordagem defensiva. Em geral, é necessário mais pessoal para conduzir uma operação ofensiva e vidas e propriedades são melhor protegidas por meio de um ataque ofensivo. Por outro 
lado, a falta de recursos necessários pode levar a uma decisão defensiva, mesmo quando um ataque ofensivo é claramente a melhor abordagem (KLAENE; LAKAMP, 2020).

No início do incidente, existe uma grande probabilidade de salvar vidas de ocupantes e extinguir o incêndio. À medida que a temperatura aumenta em uma estrutura sem ventilação, a camada de fumaça começa a encher o recinto enquanto a estrutura enfraquece, assim, a probabilidade de salvar vidas diminui e a extinção é mais difícil (KLAENE; LAKAMP, 2020).

\section{ACRÔNIMOS UTILIZADOS EM COMBATE A INCÊNDIOS}

A utilização de acrônimos relacionados aos objetivos estratégicos do combate a incêndios não é algo recente. REVAS (rescue, evacuation, ventilation, attack and salvage), originado nos Estados Unidos da América EUA, RECEOVS (rescue, exposure, confinement, extinguishment, overhaul, ventilation and salvage), também criado nos EUA, e RICE (rescue, intervention, confinement and evacuation), que surgiu no Reino Unido, são alguns exemplos (GRIMWOOD, 2017; ANGLE et al., 2020).

No RICE, cada letra indica uma decisão estratégica ou uma prioridade nas operações de combate a incêndio. Quando o comandante de socorro escolhe a opção "R", por exemplo, ele opta por uma intervenção de salvamento de vidas (Rescue), como estabelecimento rápido de uma linha de mangueiras. A opção pela letra "l" (Intervention) indica uma escolha pelo combate a incêndio, com o desenvolvimento rápido de uma linha de ataque e uma linha de suporte. Quando a definição se dá pela letra "C" (Containment), as ações visam a contenção do incêndio ou ações que limitem a propagação e 0 desenvolvimento interno e externo do incêndio e indicam que os bombeiros trabalharão para confinar o incêndio e se prepararão um ataque externo. Por fim, a escolha pela letra "E" (Evacuation) indica que será priorizada uma ação de evacuação, protegendo as rotas de fuga e escadas, se necessário. 
Recentemente foi desenvolvido nos Estados Unidos da América - EUA um acrônimo que propõe uma abordagem tática para auxiliar os bombeiros a incorporarem aprendizados provenientes das pesquisas em dinâmica do incêndio e transformar esse aprendizado em ações a serem tomadas pelos primeiros respondedores. Esse método foi denominado SLICE-RS (size-up, locate the fire, identify the flow path, cool the space from the safest location, extinguish the fire, rescue, salvage) e foi baseado em pesquisas do National Institute of Standards and Technology - NIST e Underwriters Laboratories Firefighter Safety Research Institute - UL (GRIMWOOD, 2017).

Numa conversão para o português (não uma tradução literal), podemos adotar o acrônimo ALICE-S(O)S, que remete a: avaliação da cena, localização do foco do incêndio, identificação do fluxo de ar no incêndio, combate inicial, extinção do incêndio, salvamento e salvatagem. A letra "O" presente entre as duas letras " $\mathrm{S}$ " indica tanto que as ações são emergenciais quanto para recordar ao comandante de socorro que as duas últimas ações são de oportunidade.

Grimwood (2017) expõe que o método reconhece algumas das causas mais comuns associadas a perdas de vidas de bombeiros em incêndios estruturais e incorpora orientações que não devem ser, necessariamente, implementadas na ordem listada, mas aplicadas de uma forma que priorize as ações necessárias, de acordo com a equipe e os recursos disponíveis.

A aplicação do acrônimo ALICE-S(O)S é um ótimo exemplo do momento em que a ciência encontra a prática de campo e, quando isso ocorre, muitos benefícios são fornecidos às pessoas que tomam as decisões no nível operacional acerca da maneira como devem combater os incêndios. Essa interação pode ser considerada um enorme salto qualitativo nas atividades de combate a incêndio urbano uma vez que objetiva incorporar os dados científicos obtidos nas pesquisas realizadas no NIST e no UL nas operações de resposta de emergência. 
Por meio da aplicação desta metodologia, as guarnições de combate a incêndio urbano trabalham com um nível de segurança ocupacional muito maior com consequente redução dos riscos gerais a que estão expostos. Nesse contexto deve-se entender risco de maneira ampla, desde a segurança da cena, passando pela abordagem ofensiva ou defensiva indo até a deliberação tática de ataque: interior, exterior ou transicional.

Deve-se considerar ainda que por meio desse acrônimo, e sendo este aplicado às equipes de primeira resposta, ganha-se tempo no caso da necessidade de recursos adicionais, possibilitando-se optar por acessos mais adequados ou prepará-los apropriadamente para que haja incursão das equipes pela rota mais segura.

\section{Avaliação da cena}

Trata-se da análise contínua dos problemas e condições que influenciam no desenvolvimento do incêndio. Envolve a observação da cena da ocorrência para responder às seguintes questões: o que aconteceu? o que está acontecendo? e o que vai acontecer? (IFSTA, 2013; NORMAN, 2012)

A análise dos quesitos de segurança da cena é tarefa que cada bombeiro deve realizar, apesar de muitas vezes esta atividade estar centralizada no comandante de socorro e nos chefes de guarnição, por deterem maior autoridade funcional e carregarem consigo uma responsabilidade maior. Entretanto isso não afasta o dever individual acerca do que se vê na cena de maneira pontual em nível operativo, executório da estratégia e da tática definidas.

Deve-se ressaltar ainda que a habilidade de comando, muitas vezes, não é adquirida naturalmente e mesmo militares com muitos anos de experiência podem literalmente não saber o que fazer ao se deparar com uma situação inesperada. 
Os fatores associados ao dimensionamento da cena podem mudar de incidente para incidente e são difíceis de categorizar em termos de importância. Os elementos associados com a segurança da vida são críticos e por isso são chamados fatores primários, já os fatores menos importantes são categorizados como secundários. Além disso, são as condições do incidente que irão determinar que fatores serão primários (KLAENE; LAKAMP, 2020).

Toda informação necessária para se realizar a avaliação pode ser enquadrada em 3 (três) áreas: o ambiente no qual o incidente ocorre (características construtivas da edificação, por exemplo), os recursos disponíveis (como a quantidade de pessoal) e as condições ou situação, em que o bombeiro deve considerar as condições e a situação atual (ANGLE et al., 2020).

Outro ponto relevante no contexto da avaliação da cena é o desenvolvimento de pré-planejamentos, elaborados por meio do reconhecimento de áreas de risco e de relevância (econômica, política e concentração de público). As informações coletadas neste tipo de ação permitem aos bombeiros a avaliação de cada aspecto relevante à intervenção dos bombeiros dos locais em uma condição não emergencial, além de reforçar a imagem institucional da corporação junto à população.

Por fim, o comando de operações de combate a incêndio urbano se fundamenta em fazer um bom dimensionamento da cena, sendo este aspecto fundamental, pois é o contato inicial e muitas vezes a única abordagem direta do comandante de socorro com as guarnições reunidas sendo o momento oportuno para que o comandante passe segurança em suas ordens às equipes de socorro.

\section{Localização do foco do incêndio}

As pesquisas realizadas pelo NIST e UL têm mostrado que os incêndios têm maior probabilidade de se dirigirem para um estado denominado ventilação 
limitada, significando na prática que os bombeiros podem chegar à cena de incêndio e não verem sinais claros de fogo (ISFSI, 2014).

A tarefa de localizar o incêndio é fundamental na definição das ações de combate a incêndio urbano, mas não quer dizer que seja uma atividade simples pois pode, em muitos casos, ser dificultada pela quantidade de fumaça produzida e, além disso, a própria fumaça pode ser o elemento ativo para a propagação do incêndio seja no plano vertical ou horizontal.

O comandante de socorro pode ajudar na localização do incêndio fazendo uma volta completa na edificação (360\%), ou visualizar pelo menos 3 (três) faces da edificação, buscando visualizar chamas visíveis, alta concentração de fumaça, por exemplo (ANGLE et al., 2020).

Para que o foco de incêndio possa ser localizado mais rapidamente, tem sido encorajado o uso de câmeras térmicas. $\mathrm{O}$ uso deste equipamento permite que o impedimento visual gerado pelo excesso de fumaça seja rompido e que a localização do foco de incêndio seja determinada com maior precisão, além de permitir a detecção de diferenças de temperaturas em cômodos distintos da casa e, com isso, determinar o local mais provável de localização do foco de incêndio.

\section{Identificação do fluxo de ar no incêndio}

A identificação do fluxo de ar que alimenta a propagação do incêndio, ou simplesmente flow path, não se refere somente à corrente de convecção, apesar de tal elemento fazer parte do flow path. O termo se trata do movimento de ar (frio) para dentro da edificação, bem como a fumaça, calor e chamas que se direcionam para fora da estrutura. Dessa forma, trata-se do caminho e não somente de um fenômeno físico de comportamento da matéria.

É por causa desse fluxo que se dá o movimento da fumaça e gases aquecidos de uma área de alta pressão para uma área de baixa pressão e a consequente entrada do ar externo para o local onde se encontra o foco do incêndio. 
Para que se possa controlar o flow path deve-se saber onde está(ão) a(s) entrada(s) de ar e a(s) saída(s) de fumaça (GRIMWOOD, 2017).

Algumas formas de se fazer o controle do flow path são o fechamento de portas, além do uso de dispositivos de controle de ventilação e da própria ventilação tática.

\section{Combate inicial a partir de um local seguro}

Pode-se pensar que o resfriamento do ambiente a uma distância segura seja uma opção tática demasiadamente defensiva, o que não é verdade. Aliás, mesmo quando a opção de ataque escolhida é a externa, pode se tratar de uma escolha ofensiva. Um bom exemplo disso é o ataque externo efetuado em um local tomado por chamas em que se tem o objetivo de extinção ou de atenuação das condições do incêndio, proporcionando condições favoráveis de intervenção interior (ataque transicional).

É o que afirmou o chief Eddie Buchanan, conforme Lima (2021), quando disse que o resfriamento pode ser feito de qualquer local que se possa entregar água no ambiente sob pressão. Isso pode ser feito tanto de fora, por meio de uma janela, ou de dentro enquanto a guarnição progride. Basicamente, é suavizar as condições do ambiente à medida que avança.

Dessa forma, também consegue-se atender às condições de gerenciamento de risco previstas na NFPA 1500, que trata da aceitação de risco por parte dos bombeiros para salvamento de vidas ou propriedades.

\section{Extinção do incêndio}

A questão essencial a ser respondida ao tratar da extinção é a vazão que o operador irá utilizar para extinguir o incêndio. Atualmente, como regra, atua-se no CBMDF com o uso do padrão mínimo de seleção da vazão do esguicho e raramente essa regulagem é alterada ou levada em consideração para a intervenção nos ambientes incendiados. 
Esse é um dado extremamente relevante a ser tratado quando se fala na capacidade extintora da água, ou seja, não basta que o elemento utilizado para extinguir o incêndio tenha capacidade extintora, mas é fundamental que essa capacidade seja empregada em vazão compatível para absorver a energia liberada pelo incêndio de uma determinada fonte.

Os bombeiros devem ser, portanto, encorajados a regular o padrão de vazão dos esguichos para que encontrem a melhor configuração que permita $o$ combate eficiente ao incêndio.

\section{Salvamento}

As operações de salvamento e salvatagem são autoexplicativas, no seguinte sentido: se algo puder ser salvo, deve-se salvar; seja no que concerne à vida ou ao patrimônio, guardadas as devidas proporções de prioridade entre estas.

Provavelmente as ações de salvamento são vistas como situações a serem trabalhadas no início das operações de incêndio, contudo a metodologia ALICE-S(O)S (SLICE-RS) emprega a mudança dessa perspectiva, entendendo que os bombeiros devam estar atentos a todo momento a uma possível ação de salvamento de vítimas ou de outros bombeiros.

Deve-se lembrar ainda que a vida humana tem precedência sobre quaisquer outros interesses. Dessa forma, havendo sucesso no salvamento das vítimas, mesmo que a edificação toda se perca, a operação terá sido cumprida a contento (NORMAN, 2012).

\section{Salvatagem}

A salvatagem é possivelmente o aspecto mais importante no controle de perdas patrimoniais nas atividades dos corpos de bombeiros. O manual básico de combate a incêndio do CBMDF define salvatagem como a atividade de proteção da propriedade contra danos decorrentes do próprio combate ao 
incêndio, sendo similar ao salvamento de vítimas, porém aplicado aos bens (CBMDF, 2009b).

Muitas vezes, a literatura estrangeira equipara as ações de salvatagem com as de proteção contra exposição, o que pode gerar certa confusão em decorrência do entendimento sobre o tema adotado por diversos corpos de bombeiros no Brasil. O manual básico de combate a incêndio do CBMDF diferencia uma da outra, no sentido que salvatagem é relacionada à retirada física de materiais de uma edificação com intuito de reduzir a carga de incêndio e, assim, impossibilitar a propagação do sinistro pela ausência de combustível disponível para queima.

Por outro lado, a proteção contra exposição às chamas está relacionada com a salvaguarda de materiais dentro da edificação sem a retirada física destes. Isso pode ser feito, por exemplo, molhando a superfície de materiais que estejam em pirólise ou, cobrindo os materiais com as chamadas capas de salvatagem.

\section{APLICABILIDADE DOS ACRÔNIMOS}

Lima (2021) discutiu a aplicabilidade dos acrônimos como tática de combate a incêndios por meio de entrevistas com três comandantes de bombeiros, instrutores experientes com importantes contribuições em seus países.

O chief Eddie Buchanan, ex-presidente da ISFSI, chefe do Hanover Fire and EMS em Richmond Virginia nos Estados Unidos e desenvolvedor do acrônimo SLICE-RS (ALICE-S(O)S no CBMDF), respondeu que os bombeiros de seu departamento costumavam entrar sempre pela porta da frente para um ataque interno. Agora, o treinamento objetiva que bombeiros avaliem melhor a cena e possam determinar o melhor ponto de entrada. Outro ponto importante levantado é que, atualmente, em vez de segurar a aplicação da água até que 
se pudesse combater internamente, agora 0 ataque é feito 0 mais rápido possível, o que demora muito pouco, segundo o chief.

Nessa temática consegue-se observar claramente dois aspectos do SLICE-RS, que são o "S" (size up) e o "C" (cool the space). A avaliação adequada permite a escolha do melhor ponto de acesso, que irá garantir não somente um caminho mais curto até o foco do incêndio, mas também a rota mais segura. Deve-se considerar que na escolha do acesso, a identificação do flow path é fundamental, uma vez que a entrada dos bombeiros não pode se dar pela rota de saída de gases quentes. Seja pelo risco térmico, seja pela possibilidade dos gases quentes se inflamarem e atingirem os bombeiros no meio do percurso.

Buchannan ainda afirma que os benefícios de se utilizar os acrônimos são tanto pelo treinamento inicial no aprendizado do processo quanto para servir de guia em situações de pressão. No caso específico do SLICE-RS, pelo fato de ser um novo conceito, o desenvolvimento de uma palavra ou acrônimo foi crítico, pois todos deveriam aprender tudo de uma vez. À medida que os bombeiros pegassem experiência prática, $O$ acrônimo tornar-se-ia menos importante e a memória muscular tomaria lugar. De toda forma, o conceito do acrônimo (SLICE-RS) é aplicado no treinamento de todos os novos bombeiros.

O autor Paul Grimwood, comandante aposentado da London Fire Brigade e instrutor de comportamento do fogo em ambientes confinados (CFBT), quando entrevistado, afirmou que no Reino Unido não se usa o SLICERS (ALICE-S(O)S) como padrão, apesar de ser ensinado na formação dos comandantes (na teoria) e serem feitas discussões sobre o método. Em seu país eles já dispõem de uma metodologia (acrônimo) própria utilizada há muitos anos, que é o RICE, um acrônimo empregado nas ações de comando, com poucas letras, bem disseminado no país e que, segundo o comandante aposentado, funciona bem com o tipo de edificação encontrada naquele país.

O chief Mike Clemens, comandante do Montgomery County Fire and Rescue, relatou que os acrônimos não são usados abertamente na cena de 
emergência, mas que fazem parte do treinamento dos bombeiros. Algo que já havia sido explicado pelo chefe Buchannan. O grande problema, segundo ele, é que como bombeiros, nos Estados Unidos, não há uma unidade. O sistema em si é constituído por 30.000 departamentos independentes que usam padrões e livros de texto da NFPA e que atendem às recomendações e boas práticas adotadas por essa agência e isso dificulta a implementação de uma metodologia uniforme. Afirmou ainda que, pelo fato de o CBMDF dispor de um sistema educacional centralizado e uma organização única, há uma chance maior de implementar o SLICE-RS (ALICE-S(O)S) na corporação.

\section{RESPONSABILIDADES DO COMANDANTE DE SEGUNDA RESPOSTA}

Cada nível de chamado para determinada ocorrência de incêndio requer uma quantidade específica de recursos a serem despachados. Esses recursos podem ser de quaisquer tipos: ABT (auto bomba tanque), ASE (auto salvamento e extinção), ABSL (auto busca e salvamento leve), UR (unidade de resgate), AR (auto rápido) ou AT (auto tanque), tomando como exemplo a realidade operacional do CBMDF.

Ademais, quando se trata de segunda resposta, a agilidade com que os recursos chegam é fundamental. Nesta seara, para que o comandante de socorro possa ter a real noção de que determinada solicitação será célere ou não é algo que ele deve prever ainda no deslocamento para a cena.

Dessa forma, a requisição de recursos deve ser feita assim que se tem uma boa dimensão do que está acontecendo no momento, o que pode acontecer em um futuro próximo bem como o que será necessário para evitar um comprometimento maior de vidas e patrimônio. É um erro esperar a necessidade surgir para solicitar o recurso adicional, sendo que essa tarefa compete exclusivamente ao comandante de socorro.

A assunção do comando de uma ocorrência não se dá na cena simplesmente. Aliás, esperar para assumir o comando da ocorrência ao chegar 
na cena de atendimento à emergência é um erro observado com certa frequência. Aguardar a chegada na cena para assumir o comando da operação faz com que recursos sejam despachados sem controle pelos rádio-operadores das centrais, permitindo que haja diversas pessoas concorrendo pelo protagonismo da ocorrência num momento crítico, gerando elevado ruído de informações e diversas solicitações conflitantes.

No que tange à segunda resposta, o acrônimo proposto para direcionar as ações a serem priorizadas pelo segundo comandante de socorro é o CRISE-B (ou SWARMS na sua versão em língua inglesa), cujos termos são descritos na sequência. Trata-se de uma metodologia desenvolvida no CBMDF levando em consideração os objetivos secundários no combate a incêndios, que são de responsabilidade do comandante de socorro de segunda resposta, por exemplo, um Supervisor de Área ou Superior de Dia.

\section{Controle de pessoal}

O controle de pessoal é uma tarefa muito importante a ser desempenhada nas operações de combate a incêndio urbano. Os bombeiros costumam utilizar-se sempre da máxima: "entramos juntos, saímos juntos". É necessário que se saiba onde cada bombeiro está, para que foi designado e quanto tempo ele tem para executar aquela atividade (contabilizado em termos de pressão no cilindro de ar respirável).

Dentro da realidade atual do CBMDF para que se estabeleça um sistema de controle de pessoal mínimo é necessário que sejam estabelecidos pelo menos - 3 (três) pontos de controle: o primeiro seria nas próprias viaturas de atendimento às ocorrências, sendo de responsabilidade de cada chefe de guarnição consistindo na manutenção dos militares não empregados dentro das viaturas ou junto a elas.

O segundo ponto seria o estabelecimento físico do zoneamento da ocorrência, o que garantiria controle do pessoal efetivamente empregado na 
cena. Esse zoneamento físico poderia ser feito com a utilização de fitas zebradas para o cercamento do local e o emprego de bombeiros ou policiais para controle da área.

O terceiro ponto é o controle do pessoal que efetivamente entra na zona quente, cabendo a um militar ou uma dupla controlar quem entra, a capacidade de ar do cilindro e a expectativa de tempo de trabalho na zona quente e aqueles que já saíram.

Deve-se considerar que esse sistema é paliativo, enquanto não se tem um sistema explícito de controle de pessoal na cena. A escolha por um sistema de passaporte (mais simples e acessível) ou pelo modelo rastreável deve estar ligada a um extenso programa de treinamento para que se possa ser aplicado de forma mais eficiente.

\section{Reabilitação}

Criar espaços para reabilitação dos militares nas cenas de incêndio é compreender a dimensão do desgaste físico que a atividade conjugada com o uso do equipamento de proteção individual gera nos bombeiros.

O tema foi amplamente discutido no trabalho monográfico de Cavalcanti (2012) e deve-se considerar a importância do tema reabilitação ponderando sua relevância mais do que tão somente acerca da reposição de água e eletrólitos, alimentação e descanso aos bombeiros.

Quando se fala em reabilitar um bombeiro deve-se ter em mente que o militar enfrentou situações que podem também gerar problemas de saúde a curto, médio e longo prazos, que vão desde condições mais simples como erupções cutâneas, podendo ir até golpes de calor e rabdomiólise.

Isto posto, convém que o segundo comandante de socorro pense em estratégias que permitam aos militares que saem da zona quente recebam a reidratação adequada, descanso e eventualmente avaliação por uma equipe médica. 


\section{Integridade estrutural}

A avaliação da integridade estrutural das edificações deve pautar-se em decisões práticas, como a avaliação do tempo de queima e o possível risco aos bombeiros empregados na cena. Em conjunto a essa observação, a presença da Defesa Civil é fundamental.

Nesse sentido, pode ser adotada pelo Oficial mais antigo na cena a regra dos 20 minutos de Norman (2012), que possibilitará a avaliação estrutural da edificação por meio de impressões dos bombeiros in loco ou por avaliação direta da Defesa Civil. Além disso, esse período de avaliação pode ser utilizado para ajustes na estratégia empregada, pois convém lembrar que, segundo o mesmo autor, se as ações não tiveram resultados relevantes dentro do tempo estabelecido de 20 minutos, uma mudança de abordagem deve ser empregada.

\section{Suprimento de água}

O suprimento de água é um objetivo primário nas ações de combate a incêndio urbano, pois, a priori, não se combate incêndio sem água. A água é fundamental.

Deve-se ter em mente que nem todos os locais que se atende ocorrências no Distrito Federal - DF são homogêneos, muito pelo contrário. Quando se fala da área central do DF, a disponibilidade da rede de hidrantes, bem como a quantidade de Unidades próximas facilita o suprimento de água das operações de combate a incêndio rotineiras, seja por abastecimento pelo serviço público seja pelo suprimento ofertado por viaturas.

Além disso, o fato de se ter o recurso não garante o suprimento adequado da operação. Caso o comandante de socorro não consiga conjugar a disponibilidade com a logística adequada haverá falta d'água no combate, o que consiste em uma falha de segurança grave. Nesse sentido várias técnicas podem ser utilizadas para contornar esse problema, como por exemplo a 
técnica do vaivém, sistema pião, uso de tanques, estabelecimento de viaturas próximas a hidrantes, uso de reservas técnicas de incêndio de edificações, entre outras (CBMDF, 2009b).

Além disso, deve ser feita uma avaliação estratégica que leva em consideração o tipo de edificação acometida pelo incêndio e sua localização, de modo que a avaliação acerca da brevidade do suprimento seja considerada. Um exemplo disso são os incêndios em áreas com edificações precárias, os quais exigem uma logística complexa para que o suprimento de água seja contínuo.

Outro aspecto que pode e deve ser trabalhado pelo comandante de socorro junto a seus militares é o controle da vazão dos esguichos, principalmente quando - ainda - não se tem um sistema de aporte de água adequado. Disso decorrerá a abordagem escolhida com vistas a controlar ou extinguir o incêndio de modo a fornecer algum tempo no estabelecimento de um sistema de suprimento que garanta o combate ininterrupto sem que haja riscos de corte do fornecimento.

\section{Emergência com bombeiros - Equipe de resgaste de bombeiros}

A instituição de um protocolo de mayday, ou seja, de retirada imediata dos bombeiros de uma eventual emergência na cena é fundamental para a segurança das operações.

Os eventos emergenciais normalmente estão ligados a alguma situação adversa envolvendo bombeiros em cena. Dessa forma os protocolos de mayday devem estar intimamente relacionados com o estabelecimento de equipes de resgate de bombeiros - ERB (ou RIC/RIT) na cena de incêndio.

Klaene e Lakamp (2020) afirmam que as Rapid Intervention Crews (RICs) devem ser estabelecidas em todos os estágios do incidente, começando com a primeira unidade que chega usando um processo two-in / two-out. 
Como uma orientação de aplicação do recurso, Angle et al. (2020) propõem que a viatura de salvamento de segunda resposta seja empenhada na missão de resgate de bombeiros.

O Supervisor de Área (ou de forma mais geral, o comandante de socorro de segunda resposta) deve compreender que a definição de uma equipe específica de salvamento de bombeiros é um aspecto que atende as prioridades do combate ao incêndio.

Toda atividade de combate a incêndio urbano envolve risco à vida, mesmo aquelas em que não há vidas a serem salvas. Nesse caso, as vidas em risco são as dos bombeiros e elas devem ser priorizadas antes de qualquer outro bem.

É um risco para a segurança dos bombeiros postergar a formação de uma equipe de resgate de bombeiros para o momento em que a situação surgir. É o que afirma o módulo 4 do manual básico de combate a incêndio urbano do CBMDF ao reiterar que o comandante do socorro deve antecipar necessidades para prevenir problemas ou mesmo solucioná-los mais rapidamente (CBMDF, 2009C).

\section{Busca}

A atividade de busca nas operações de incêndio constitui-se em elemento fundamental para garantir que nenhuma vítima deixará de ser resgatada ou, em última análise, de ser encontrada.

As guarnições de combate a incêndio urbano devem admitir que sempre deverão executar atividades de busca, como regra, mesmo que haja confirmação da não existência delas no momento da chegada à cena.

No Brasil, é comum associar a atividade de busca ao fato de se ter uma linha de mangueira como proteção, uma vez que os manuais estabelecem essa rotina como um objetivo secundário do combate a incêndio urbano. Entretanto essa conduta não encontra amparo nas definições mais atuais do termo na literatura estrangeira. Sabe-se que existem técnicas de busca que podem ser 
executadas sem haver linhas de mangueiras prontas e um exemplo bastante claro disso é a técnica VEIS - Vent-Enter-Isolate-Search (ISFSI, 2014).

Nesse sentido, a segunda resposta deve empenhar esforços para executar ou auxiliar a execução de atividades de busca nas operações de combate a incêndio o quanto antes. $O$ uso de câmeras térmicas bem como 0 seguimento das técnicas de varredura de ambientes, por exemplo, por meio da técnica da mão direita/esquerda, largamente conhecida nos corpos de bombeiros, são fundamentais para que os bombeiros possam fazer uma pesquisa detalhada dos ambientes, com foco naqueles ambientes em que as vítimas têm maior probabilidade de serem encontradas.

$\mathrm{O}$ comandante do incidente deve estar ciente que chegar à cena com rapidez, definir um plano de busca e conhecer os locais em que as vítimas têm maior chance de serem encontradas são aspectos fundamentais no sucesso desta atividade.

Ademais, o emprego de equipes especializadas em busca, salvamento e combate a incêndio, além de militares experientes chefiando as diversas equipes empregadas também fazem muita diferença no resultado obtido nessa tarefa, por razões como: experiencia adquirida, nível de treinamento elevado, especialização nas áreas e emprego de técnicas que podem não ser conhecidas pela prontidão em geral.

No que tange aos tipos de busca, os conceitos de busca primária e secundária, explícitos inclusive no manual básico de combate a incêndio urbano, já são conhecidos entre os militares especializados do CBMDF, mas não pela tropa em geral. Somam-se a isso aspectos mais específicos como as marcações nas portas e a execução das buscas primária e secundária por equipes diferentes. Dessa forma, passa a ser função do comandante do incidente (pessoalmente ou por meio do oficial de operações) determinar aos chefes de guarnição como o trabalho deverá ser executado. 


\section{CONSIDERAÇÕES FINAIS}

Conforme Reeder e Milan (2014), a pesquisa (entendida pelas inovações) não é um ataque à tradição nem uma declaração de que se fez algo da maneira errada. Tudo aquilo que é feito na atividade de combate a incêndios deve ser avaliado constantemente, mantendo o que funciona, descartando o que não funciona e modificando outras para aumentar sua eficácia. É nesse contexto que os acrônimos entram: são elementos objetivos rapidamente aplicáveis na cena de socorro.

Tanto o ALICE-S(O)S ou SLICE-RS (acrônimo para delineamento das atividades a serem desempenhadas em primeira resposta) quanto o CRISE-B ou SWARMS (acrônimo de segunda resposta) não têm a intenção de serem norteadores das fases do combate a incêndio. O objetivo dessas ferramentas é fornecer rapidamente ao comandante de socorro respostas às situações com que ele se depara no transcorrer das ocorrências de incêndio que, nesse caso, é responder ao questionamento: "o que eu vou fazer quando chegar lá"?

Essa análise independe da dimensão da ocorrência e é tudo sobre o que está acontecendo no momento da tomada de decisão: "quais são as minhas prioridades?", "quais são os meus recursos, como posso empregá-los melhor?" e "vou precisar de apoio?".

Exemplos clássicos desse tipo de situação são observados quando o comandante de socorro solicita viaturas sem ter dimensão da ocorrência, gerando um caos na chegada ao endereço, sem nenhum preparo para receber os recursos que chegam e bombeiros fora das viaturas querendo atuar por conta própria ou então quando se dispensa os recursos sem que seja feito um dimensionamento adequado da cena solicitando os mesmos recursos poucos minutos depois. Nesse momento o comandante de socorro já perdeu o comando e a resposta já fracassou antes mesmo de começar.

O emprego desses acrônimos auxilia as corporações de bombeiros a mirar os resultados das pesquisas sobre o comportamento do fogo para uma 
Revista Científica do Corpo de Bombeiros Militar de Pernambuco

Artigo Publicado no Vol.07 N.19 - Julho a Dezembro 2021 - ISSN 2359-4829

Versão on-line disponível em: http://www.revistaflammae.com

melhor tomada de decisão em termos de estratégia e táticas na cena do incêndio urbano, melhorando a gestão nas operações e aumentando a qualidade do serviço prestado à sociedade.

\section{REFERÊNCIAS}

ANGLE, James S.; GALA, Michael F.; HARLOW, T. David; LOMBARDO, William B.; MACIUBA, Craig M. Firefighting strategies and tactics. 4. ed. Burlington, MA, EUA: .Jones \& Bartlett Learning, 2020.

BRYANT, G. Keith. President's Letter: Command and Tough Decisions. International Fire Chiefs Association. Chantilly, VA, 2014. Disponível em: https://bit.ly/3gi0Beo. Acesso em: 21 ago. 2021

CAVALCANTI, Paulo Fernando Leal de Holanda. Parâmetros para rotinas de trabalho nas áreas de reabilitação das ocorrências de combate a incêndio estrutural em edificações atendidas pelo Corpo de Bombeiros Militar do Distrito Federal: uma análise baseada na administração do estresse térmico pelo calor. Monografia (Curso de Aperfeiçoamento de Oficiais - CAO) CBMDF, Brasília, 2012.

CBMDF - CORPO DE BOMBEIROS MILITAR DO DISTRITO FEDERAL. Manual básico de combate a incêndio: módulo 1 - comportamento do fogo. 2 ed. Brasília, 2009a. Disponível em: https://bit.ly/2XG7n7f. Acesso em: 21 ago. 2021.

CBMDF - CORPO DE BOMBEIROS MILITAR DO DISTRITO FEDERAL. Manual básico de combate a incêndio: módulo 3 - técnicas de combate a incêndio. 2. ed. Brasília, 2009b. Disponível em: https://bit.ly/2XG7n7f. Acesso em: 21 ago. 2021.

CBMDF - CORPO DE BOMBEIROS MILITAR DO DISTRITO FEDERAL. Manual básico de combate a incêndio: módulo 4 - tática de combate a incêndio. 2. ed. Brasília, 2009c. Disponível em: https://bit.ly/2XG7n7f. Acesso em: 21 ago. 2021.

CBMDF - CORPO DE BOMBEIROS MILITAR DO DISTRITO FEDERAL. Manual de perícia em incêndios e explosões: conhecimentos gerais. Brasília, 2019. Disponível em: https://bit.ly/3838Y9e. Acesso em: 21 ago. 2021.

CFOA. The Future of Incident Command. Birmingham, Inglaterra, 2015. Disponível em: https://bit.ly/3B21Rdu. Acesso em: 21 ago. 2021. 
Revista Científica do Corpo de Bombeiros Militar de Pernambuco

Artigo Publicado no Vol.07 N.19 - Julho a Dezembro 2021 - ISSN 2359-4829

Versão on-line disponível em: http://www.revistaflammae.com

DRYSDALE, D. An introduction to fire dynamics. 3 ed. London: John Wiley \& Sons, 2011.

FEMA. Risk Management Practices in the Fire Service. 1. ed. Emmitsburg: U.S. Fire Administration, 2018. Disponível em: https://bit.ly/3D63R6h. Acesso em: 21 ago. 2021.

GRIMWOOD, Paul. Euro firefighter. 1. ed. Huddersfield: Jeremy MillsPublishing Limited, 2008.

GRIMWOOD, Paul. Euro firefighter 2: Firefighting Tactics and Fire Engineer's Handbook. 1a ed. Huddersfield: D\&M Heritage Press, 2017.

IFSTA - INTERNATIONAL FIRE SERVICE TRAINING ASSOCIATION. Essenials of firefighting and fire department operations. 6. ed. Oklahoma: Fire Protection Publications, 2013.

ISFSI - INTERNATIONAL SOCIETY OF FIRE SERVICE INSTRUCTORS. Principles of modern fire attack - SLICE-RS overview. 2014. Vídeo (18min e 49seg) publicado pelo canal ISFSI. Disponível em: https://bit.ly/3gm9vrb. Acesso em: 21 de set. 2020.

KERBER, S. Analysis of Changing Residential Fire Dynamics and Its Implications on Firefighter Operational Timeframes. Fire Technology 48, 865891 (2012).

KLAENE, Bernard J; LAKAMP. Thomas C. Structural Firefighting: Strategy and Tactics. 4. ed. Burlington: Jones \& Bartlett Learning, 2020.

LENTINI, J. J. Scientific protocols for fire investigation. 2 ed. New York: Taylor \& Francis, 2013.

LIMA, Eduardo de A. Emprego de acrônimos para o direcionamento das ações nas operações de combate a incêndio urbano: uma análise dos eventos prováveis em primeira e segunda respostas. Monografia (Curso de Aperfeiçoamento de Oficiais - CAO) - CBMDF, Brasília, 2021. Disponível em: https://bit.ly/3z8XT2b. Acesso em: 21 ago. 2021.

MORRIS, Gary. Rules of Engagement for Incident Commanders: Conduct a Risk Assessment and Implement a Safe-Action Plan. Scottsdale, AZ, 2012.

NORMAN, John. Fire Officer's handbook of tactics. $4^{\mathrm{a}}$ ed. Tulsa, Oklahoma, EUA: Fire Engineering Bk Dept, 2012.

PRZIBOROWSKI, Steve. Avoiding Chaos. Fire Rescue Magazine. Santa Clara, Califórnia, EUA, 2015. Disponível em: https://bit.ly/3B0pFP3. Acesso em: 21 ago. 2021. 
QUINTIERE, J. G. Principles of fire behavior. New York: Delmar Publishers, 1998.

REEDER, Forrest; MILÁN, Kenya. Effective Cooling \& Extinguishment Strategies. Fire Rescue Magazine, volume 9, edição 3, 2014. Disponível em: https://bit.ly/3ARIK5Y. Acesso em: 21 ago. 2021.

UL FSRI, 2018. 1 vídeo ( 1 min e 29 seg) - Tactical consideration: there is no substitute for knowledge. Publicado pelo canal ULfirefightersafety. Disponível em: https://www.youtube.com/watch?v=qWI2n7B9Mcg. Acesso em: 20 set. 2020.

WAGNER, Robert. Practical risk management for firefighters. Fire Rescue 1, EUA, 2019. 